\title{
NÃO SEI SE VOU OU SE FICO. EMPREENDER OU PERMANECER NO EMPREGO?
}

\author{
TO GO OR NOT TO GO? \\ UNDERTAKE OR REMAIN IN EMPLOYMENT?
}

FERNANDA ELVIRITA CASSOL

Universidade do Oeste de Santa Catarina - Unoesc

Mestre em Administração - Unoesc

Orcid: https://orcid.org/0000-0002-4655-1700 / E-mail: fercassoll@gmail.com

Endereço: Av. Nereu Ramos, 3777-D - Bairro Seminário

Chapecó - SC - CEP 89813-000

\section{LUCCAS SANTIN PADILHA}

Universidade do Oeste de Santa Catarina - Unoesc

Doutorando em Administração - Unoesc

Orcid: https://orcid.org/0000-0002-5786-3259 / E-mail: luccas_santin@hotmail.com

NAIANE MODRI FUZINATTO

Universidade do Oeste de Santa Catarina - Unoesc

Mestre em Administração - Unoesc

Orcid: https://orcid.org/0000-0002-6386-5568 / E-mail: naiane.fuzinatto@unoesc.edu.br

\section{DARLAN JOSE ROMAN}

Universidade do Oeste de Santa Catarina - Unoesc

Doutor em Administração - UFSC

Orcid: https://orcid.org/0000-0002-2004-8736 / E-mail: darlan.roman@unoesc.edu.br

Submissão: 06/08/2019. Revisão: 13/05/2020. Aceite: 07/07/2020. Publicação: 03/08/2020. DOI: http://dx.doi.org/10.22277/rgo.v13i3.5000

\begin{abstract}
RESUMO
Este caso para ensino foi desenvolvido para auxiliar estudantes de graduação em Administração a refletir sobre a tomada de decisão para o empreendedorismo, os impactos das decisões organizacionais e a capacidade empreendedora. O caso apresenta a história do Eduardo, um jovem com emprego e garantias trabalhistas, que se deparou com a oportunidade de mudar sua carreira profissional. No entanto, precisa analisar o mercado, seus conhecimentos técnicos e suas habilidades para tomar uma decisão assertiva. Neste contexto, se depara com o seguinte dilema: seguir empregado, tendo sua carreira definida pelo empregador e as garantias asseguradas em lei, tais como receitas mensais não variáveis, horários predeterminados, férias, entre outros; ou empreender no setor de prestação de serviços por meio do coaching, assumindo todos os riscos e responsabilidades do empreendimento. Este caso está relacionado aos temas de tomada de decisão e empreendedorismo.
\end{abstract}

Palavras-chave: Tomada de decisão. Empreendedorismo. Caso para ensino. 


\begin{abstract}
This teaching case aims to help undergraduate students in Business Management to reflect on decision-making for entrepreneurship, impacts of organizational decisions and entrepreneurial capacity. The case presents Eduardo's story, a young man with a job and labor guarantees, faced with the opportunity to change his professional career. However, he needs to analyze the market, his technical knowledge, and his skills to make an assertive decision. In this context, he faces the following dilemma: to remain employed, having his career defined by the employer and the guarantees ensured by law, such as non-variable monthly income, predetermined labor hours, vacations, among others; or undertake in the service provision sector through coaching, assuming all the risks and responsibilities of the enterprise. This case relates to decision-making and entrepreneurship.
\end{abstract}

Keywords: Decision-making. Entrepreneurship. Teaching case.

\title{
1 INTRODUÇÃO
}

Em pleno verão de 2018, durante uma ensolarada e produtiva tarde, o jovem Eduardo elaborava uma proposta de negócio para um novo cliente da empresa para a qual trabalhava. Nesta proposta ele tinha como desafio desenvolver um modelo diferenciado de treinamento e desenvolvimento empresarial. Em meio a ideias, papéis, livros e conceitos atuais do mercado de negócios, Eduardo estruturou uma proposta inovadora. Apresentou-a primeiramente para seu gestor, a fim de obter sua aprovação antes de encaminhar para o cliente. Fez uma apresentação arrojada, visto que tinha como princípios e valores pessoais a criatividade e a inovação. Todavia, antes mesmo que pudesse concluir a proposta, sua gestora o interrompe e decreta: "não existe inovação nessa proposta. Você não é criativo, não tem nada de novo". Esta afirmação o deixou perplexo e desconfortável, pois afrontava seus valores pessoais e profissionais. Aquelas palavras proferidas pela gestora atingiram seus pensamentos na velocidade de um raio, o que acendeu um alerta de que algo poderia estar errado.

Inconformado com as dúvidas, Eduardo buscou respostas em um curso de autoconhecimento, que o despertou para outra atividade profissional, para a qual Eduardo não imaginava que possuísse habilidades: o coaching. Conforme Peterson (1996) coaching é o processo de equipar as pessoas com as ferramentas, o conhecimento e as oportunidades necessárias para que elas se desenvolvam e se tornem mais eficazes. O conhecimento desta nova oportunidade fez Eduardo perceber que poderia obter um complemento em sua remuneração, visto que aplicaria as técnicas em horários alternativos, que não interfeririam em suas atividades na empresa que estava contratado. A execução das atividades extras e a utilização de mídias sociais estavam lhe abrindo novas portas. Entretanto, chegou o momento em que seu gestor determinou: para continuar com a atividade extra, Eduardo precisaria se desligar da empresa, pois a atividade de coaching estava interferindo diretamente no seu trabalho. E então, o que fazer? Qual a melhor escolha para Eduardo? Continuar com a carreira na empresa como funcionário e renunciar à remuneração extra, ou renunciar às garantias de um emprego fixo, mudar de carreira e tornar-se um empreendedor?

Nos capítulos seguintes será apresentado o detalhamento das informações necessárias para embasar a tomada de decisão. 


\section{TRAJETÓRIA PROFISSIONAL}

Eduardo iniciou sua trajetória profissional aos 14 anos como jovem aprendiz no ramo do comércio, executando atividades relacionadas a atendimento ao cliente e controle de vendas e estoque. A partir desta sua primeira experiência no mercado de trabalho, matriculou-se em um curso técnico de mecânica industrial, logo após concluir o ensino médio. No entanto, seu verdadeiro desejo era cursar o bacharelado em Arquitetura. Todavia Eduardo não possuía condições financeiras para ingressar em um curso de graduação particular - única opção disponível em sua cidade. Além disto, Eduardo encarou a pressão familiar para prosseguir os estudos e optar por um caminho que lhe assegurasse uma atividade laboral com carteira assinada. Eduardo é descendente de agricultores que migraram para a cidade, e passaram a trabalhar como zelador e empregada doméstica. Isto gera um profundo orgulho em Eduardo, pois foi criado sob forte influência de valores pessoais, morais e éticos. Neste contexto, o curso técnico lhe parecia ser a melhor opção.

Nos primeiros meses do curso técnico, Eduardo passou a trabalhar como recepcionista de uma empresa e logo percebeu que possuía aptidão para trabalhar diretamente com o público. Ademais, Eduardo observou que na empresa em que estava atuando, as vagas disponíveis nos processos seletivos internos requisitavam como qualificação profissional cursos relacionados à administração, contabilidade e economia. Estes fatores levaram Eduardo a perceber que já não mais se identificava com o curso de mecânica industrial, e contribuíram para sua primeira decisão profissional: abandonar o curso técnico e prestar vestibular para um dos cursos solicitados nos processos seletivos da empresa. Contudo, para que isso se concretizasse, Eduardo precisou economizar durante um ano para arcar com as despesas iniciais de matrícula e materiais solicitados na graduação em Administração.

Passado algum tempo cursando Administração, Eduardo foi aprovado em um processo seletivo interno da empresa em que seguia atuando, assumindo o cargo de Auxiliar Administrativo. Após este evento, Eduardo permaneceu na empresa durante seis anos, e neste período evoluiu profissionalmente, galgando cargos de níveis mais elevados, mudando de setores, assumindo diferentes responsabilidades, até chegar ao cargo de Analista Administrativo. Neste cargo, atuava no setor estratégico e contava com forte apoio e incentivo de sua coordenadora. Eduardo afirma que ela era a pessoa que mais acreditava nele como profissional, que o auxiliava a conquistar promoções e evoluir na empresa. Conforme relatou Eduardo, ela o fez crescer, Ihe ofertava desafios e acreditava nas capacidades dele. Segundo Eduardo, a coordenadora Ihe direcionava bem, pois queria o desenvolvimento da equipe. Por vezes lhe tirava algumas funções e Ihe atribuía outras, baseada no perfil de Eduardo como profissional.

Todavia, Eduardo perdeu esse apoio constante e próximo devido a transferência de sua coordenadora para um outro setor da empresa, deixando o setor em que atuava anteriormente - o mesmo de Eduardo, sem coordenação. Em virtude de sua experiência, Eduardo tomou a frente em diversas situações conflituosas que surgiram após a saída da coordenadora, no entanto, não pôde ser promovido automaticamente pela falta de uma formação teórica concluída, exigida pela empresa. Neste ponto, o gestor do setor propõe que Eduardo siga registrado como analista, porém atuando no setor e assumindo as responsabilidades do cargo de coordenação, até a conclusão de seu curso de graduação em Administração. A partir do momento que obtivesse o diploma, seria oficialmente promovido a coordenador. Após algum tempo, já com o diploma de Administrador em mãos, Eduardo foi promovido ao cargo prometido por seu gestor, e apresentado à toda a equipe como novo coordenador. 
Diante das atividades e decisões do novo cargo, Eduardo lembra que enfrentou dificuldades, especialmente por não possuir conhecimentos técnicos em áreas específicas, como, por exemplo, a informática. Isso fez com que buscasse informações de modo autônomo, como autodidata. Além disso, Eduardo ressalta que se sentia imaturo e desprovido de competências para ocupar o cargo. $O$ cargo de coordenador exige tomadas de decisão que impactam em processos e pessoas, e Eduardo enfrentou seu primeiro grande desafio ao necessitar efetuar a demissão de um amigo. Baseando-se apenas nos conhecimentos obtidos na graduação, efetuou o procedimento de modo objetivo e direto, porém obteve como resposta atitudes rudes de revolta por parte do funcionário demitido. Percebeu, então, que não havia agido da melhor maneira possível, apesar de fazer o que havia aprendido por meio de teorias.

Além disso, Eduardo precisou se adaptar ao novo contexto dos clientes e suas exigências e reclamações, bem como às atividades de fechamento de contratos, contratação de estagiários e colaboradores, atenção às demandas da diretoria, construção de relatórios, cobrança, gerenciamento de equipe, entre outros. E em meio às atividades diárias, deparouse com a desmotivação de alguns colaboradores, sem, contudo, identificar as razões para esta conduta. O perfil de liderança adotado por Eduardo era mais informal, tinha as relações com os colegas de trabalho mais aberta, com pouca pressão, enquanto a empresa queria um perfil mais ativo e autoritário. Esta divergência no modo de atuação fez com que Eduardo questionasse sua permanência na empresa. Acreditava que poderia não estar no lugar certo. Alguns meses mais tarde teve seu contrato de trabalho rescindido sob a alegação de uma reestruturação técnica do setor, e subsequente alteração na direção, apesar de ser considerado um ótimo colaborador. A demissão foi inesperada e encerrou com os planos de Eduardo de aplicar na empresa os conhecimentos que vinha adquirindo em um curso de pósgraduação em Projetos que havia ingressado há pouco tempo, assim como de outros cursos de aperfeiçoamento que havia feito para atender às demandas do cargo. O processo de aceitação deste evento foi árduo para Eduardo.

Nas semanas seguintes, iniciou a busca por um novo trabalho, porém os salários oferecidos pelo mercado eram a metade do que ganhava no cargo de coordenador, o que lhe desanimou. Em busca por recolocação, realizou consultorias na área da saúde em uma rede hospitalar, uma atividade pontual, sem estabilidade. Em função das consultorias, recebeu um convite de um professor da graduação para trabalhar com projetos em consultoria empresarial, na captação de empresas, projeto de marketing, cliente oculto, pesquisa de mercado. Na nova atividade atendia clientes de três estados, e recebia por produtividade. Suas atribuições incluíam captação de clientela, apresentação da proposta, negociação do contrato, diagnóstico e desenvolvimento do plano de ação, implementação das ações e fechamento da consultoria. Essa gama de atividades possibilitou que Eduardo desenvolvesse uma visão sistêmica e gerencial. Eduardo afirma, em suas próprias palavras: "aprendi muito sobre o processo, rotina, trabalhar com pessoas, com o meu marketing pessoal. Foi trabalhando nessa consultoria que eu tive que me posicionar de modo mais formal em apresentações e tive que olhar para minha comunicação".

Após um ano como consultor, Eduardo recebeu uma proposta de uma imobiliária para trabalhar com gestão de condomínios. Aceitou a oferta devido ao salário atrativo e a ausência da necessidade de viagens constantes. Era uma atividade com horário determinado para entrada e saída, sem trabalhos extras. A empresa era familiar com uma gestão engessada, que inicialmente se mostrou aberta à implantação de uma gestão profissionalizada, com processos padronizados, porém havia conflitos de valores pessoais e organizacionais, não havia diálogo 
entre o proprietário e os colaboradores. Assim, apesar dos benefícios, Eduardo optou por se desligar do quadro de colaboradores após o período de experiência. Poucos meses depois, Eduardo foi aprovado em um processo seletivo como coordenador de cursos na área de gestão, ficando responsável pelas decisões de execução, planejamento, relacionamento com professores, alunos e clientes corporativos.

\section{1 CONFLITO PESSOAL E EMPRESARIAL}

A empresa em que Eduardo atua possui processos padronizados e uma gestão participativa, constituindo oportunidade de desenvolvimento de várias habilidades no processo de gestão, tais como coordenar pessoas, gerenciar conflitos em sala de aula e gerenciar custos e materiais necessários para executar o planejamento das aulas. Para Eduardo isto é uma grande oportunidade de aprendizagem, conforme relata: "pensar em atividades diferentes sempre fez parte do meu processo de criatividade. Para mim, é uma das principais competências que um líder precisa ter e eu, enquanto gestor, sempre precisei muito, até porque sempre quis estar em áreas mais dinâmicas".

A dinamicidade desta empresa proporcionou Eduardo trabalhar com projetos na área pública e privada, e com públicos diferentes das suas experiências anteriores. Suas atividades estão ligadas diretamente com o cliente final, e por meio destas obtém reconhecimento pelo trabalho realizado. Eduardo atua nesta empresa há aproximadamente cinco anos e seu setor passou por diversas mudanças, dentre elas a rotatividade de gestores e a adaptação à diferentes estilos de liderança. Durante estas mudanças de gestão a empresa abriu alguns processos seletivos, e por duas vezes Eduardo se inscreveu. Porém, não obteve aprovação em nenhum deles. Este fato culminou em desmotivação para o jovem de 31 anos que já havia vivenciado um histórico de crescimento contínuo na primeira empresa. Entretanto, continuou a desenvolver suas atividades, mesmo com o desconforto que passou a sentir - especialmente na última troca de gestão, uma vez que se considerava mais bem preparado que o candidato aprovado. Segundo Eduardo, "a última mudança foi o momento que me deixou frustrado. Eu via gestores no cargo acima de mim que não tinham as competências que o cargo exige, e me via muito mais preparado para aquele cargo do que as pessoas que entravam. Isso mexeu muito comigo, mas também me despertou para outras coisas".

A partir desse momento, Eduardo buscou um curso de autoconhecimento para entender por que não havia conseguido a promoção, já que se percebia preparado para tal. No decorrer do curso, percebeu que gostava de se comunicar com as pessoas de forma diferente, além de evidenciar o processo criativo. Ficou intrigado com a descoberta e ao final do curso solicitou uma análise com o professor, que o incentivou a fazer outro curso complementar para se certificar deste novo caminho. Os cursos o levaram a obter uma formação em coaching pessoal e empresarial, contribuíram no desempenho de suas atividades frente à coordenação.

Durante o processo de formação em coaching, Eduardo precisava realizar algumas tarefas e entregar para os treinadores a fim de obter sua certificação. Então, realizou as atividades com seus amigos e colegas mais próximos. Durante este processo os amigos indicaram para outras pessoas e para pequenas empresas. Inicialmente, Eduardo realizou as atividades de coaching para estas indicações somente para concluir a formação, no entanto, sua forma de trabalhar o coaching foi muito bem recebida. Desta forma, Eduardo recebeu convites para aplicar a técnica durante os períodos em que não estava atuando na empresa. Objetivando uma complementação da remuneração e se tornar conhecido no ramo, Eduardo utilizou as mídias sociais para contribuir com as pessoas que precisavam de um 
direcionamento de carreira, de liderança, de relacionamento ou mesmo atingir seus objetivos pessoais.

Neste momento, a empresa em que Eduardo trabalha iniciou um processo de inovação no atendimento de seus clientes, buscando atingir outros nichos de mercado. Para Eduardo, a nova formação facilitou esse direcionamento. Assim, a política adotada pela empresa se estendia a todos os setores, especialmente aos colaboradores de atendimento direto ao cliente, atividade desempenhada por Eduardo. Após várias capacitações, Eduardo recebeu a missão de desenvolver uma proposta para um cliente de acordo com o novo modelo estabelecido pela empresa. Passados alguns dias de trabalho e dedicação na construção da referida proposta, Eduardo marcou uma reunião para apresentar sua proposta a seu gestor, primeiramente. "Eu estava nervoso, com um frio na barriga. Olhei para a sala e vi todos meus colegas presentes, com aquele olhar apreensivo. A gestora então me sinaliza com a cabeça e eu início a explanação. Passados cinco slides, ela me interrompe bruscamente e diz não existir inovação em minha proposta", conforme relata.

As palavras da gestora o deixaram atônito, afinal, uma de suas principais habilidades é o processo criativo. Desta forma, Eduardo percebeu que suas características profissionais não estavam condizentes com as necessidades da empresa. Além disto, outros conflitos iniciaram por conta de sua ocupação extra - o coaching, visto que, na visão de sua gestora, poderia concorrer indiretamente com a atividade fim da empresa. A gestora então remanejou algumas atividades que estavam sob sua competência e lhe atribuiu outras. Eduardo, percebendo a situação, buscou a direção para conversar. Foi então que descobriu que se encontrava em um momento de escolha profissional: continuar como coordenador na empresa e renunciar a suas atividades extras, ou se desligar da empresa e empreender no ramo de coaching.

\subsection{DILEMA DO EDUARDO: SEGUIR A CARREIRA OU EMPREENDER EM UM NOVO MERCADO?}

Após a conversa com a direção, Eduardo estava diante de uma decisão profissional importante em sua carreira e precisava avaliar as situações. A estabilidade na empresa lhe permitia fazer planos financeiros, pois ao final do mês sabia qual o valor de que poderia dispor. Além disso, a empresa oportuniza a todos os colaboradores constantes formações e capacitações, a fim de manter a equipe atualizada. O contrato de trabalho garante proteção social ao trabalhador, como seguro-desemprego, auxílio-doença, salário-família, férias, décimo terceiro e aposentadoria. Além dos benefícios garantidos pela legislação, a empresa também possui convênio de saúde e odontológico, auxílio medicamento, bolsa de estudos e programa de descontos em diversos serviços. A remuneração de Eduardo é de 4,5 salários mínimos. Os horários de trabalho são fixos, sem a necessidade de desenvolver atividades fora da empresa ou em períodos diferentes dos pré-estabelecidos via contrato, além do suporte e condições estruturais para a realização das atividades atreladas ao cargo. Conforme relata Eduardo, "eu gosto muito de trabalhar aqui, gosto da forma da metodologia que é trabalhada. Levo muito como experiência, aprendi muito, cresci muito, me desenvolvi como ser humano, como profissional. Tenho muitos contatos, o clima de trabalho é bom, tenho muitas relações que hoje me dão suporte, além dos amigos".

A família de Eduardo é conservadora e sempre defendeu a estabilidade do emprego. Além disso, nenhum de seus entes se aventurou no campo do empreendedorismo. Desta forma, Eduardo não possui parâmetros comparativos em seu círculo familiar.

Pesquisas dos Estados Unidos apontam que mais de 40 mil executivos possuem coaches (aprendizes), segundo dados da Revista Fortune. Já no Reino Unido, 88\% das organizações utilizam esta ferramenta, conforme a Bristol University. No Brasil, o cenário não 
é muito diferente. A Pontifícia Universidade Católica de Campinas realizou uma pesquisa com 10 executivos, divulgada pela revista Você S/A (2009), que após passarem por processo de coaching, $100 \%$ deles aperfeiçoaram sua capacidade de ouvir; $80 \%$ melhoraram a flexibilidade; $80 \%$ aprenderam a aceitar melhor as mudanças; e $70 \%$ evoluíram a capacidade de se relacionarem. Estes sites também afirmam que os executivos que passaram por este treinamento melhoraram $90 \%$ sua produtividade, $80 \%$ se mostraram mais abertos a mudanças organizacionais e 70\% conseguiram melhorar o ambiente e o relacionamento no trabalho, segundo matéria da Folha de São Paulo. Só a Sociedade Brasileira de Coaching - SBC (2019), que se anuncia como pioneira no tema no Brasil, e que atua desde 1999, informa que já formou mais de 35 mil alunos em coaching. Este dado comprova que o coaching é um mercado em expansão.

Segundo a SBC (2019), um coach cobra em média R\$ 6 mil reais por coachee, sabendo que um processo de coach é de 8 a 12 sessões, possui um preço médio de 500,00 reais por sessão. Todavia, tais dados não destacam suas referências em níveis de experiência e o tempo de atuação no mercado dos profissionais da área e não consideram a abrangência dos projetos, visto que é um elemento variável, pois deve atender a necessidade da empresa.

Entretanto, no Brasil a prática ainda é pouco explorada. Conforme entrevista dada à revista Exame, o presidente da International Coaching Federation - ICF (2013) no Brasil, José Augusto Figueiredo afirma que na América do Norte e Europa, a proporção de coaches por habitantes é de quarenta para cada milhão. Já no Brasil, o número cai para quatro coaches por milhão de habitantes, ficando abaixo da média mundial de sete coaches por milhão. A ICF acredita que há espaço no cenário brasileiro para o crescimento da profissão. No entanto, alerta para o surgimento de profissionais falsamente intitulados como coaches que dizem prestar esse serviço e ludibriam seus clientes. Além disso, a escassez de fontes de informação seguras sobre o coaching dá margens para o surgimento desses falsos profissionais; o cliente teria dificuldades para saber ao certo as atribuições de um coach e como distinguir um profissional capacitado de um não qualificado (ICF, 2013).

De acordo com o Sebrae, a atuação no mercado de prestação de serviços em consultoria exige que o profissional possua amplo conhecimento técnico, visto que as empresas contratantes são seletivas e exigentes quanto a qualidade e o resultado (SEBRAE, 2018). Alguns fatores podem gerar aumento de demanda como: busca de novos conhecimentos e de inovações pelas organizações para enfrentar a globalização da economia; necessidade de criar e consolidar vantagem competitiva; necessidade de implantar um processo de aprendizagem organizacional, progressivo da realidade interna e externa da empresa, visando um processo de melhoria contínua e sustentada; proporcionar metodologias, técnicas, informações e processos que suportem os executivos das empresas tomarem suas decisões com qualidade (SEBRAE, 2018).

O exercício das técnicas de coaching requer a formalização de uma empresa de prestação de serviços, com o registro da empresa nos seguintes órgãos: Junta Comercial; Secretaria da Receita Federal (CNPJ); Secretaria Estadual da Fazenda; Prefeitura do município para obter o alvará de funcionamento e licença sanitária; enquadramento na entidade sindical patronal (empresa ficará obrigada a recolher por ocasião da constituição e até o dia 31 de janeiro de cada ano); cadastramento junto à Caixa Econômica Federal no sistema "Conectividade Social - INSS/FGTS"; corpo de bombeiros militar; prefeitura para obtenção de inscrição municipal, perfazendo um custo inicial de $\mathrm{R} \$ 1.100,00$ mais honorários mensais na média de $\mathrm{R} \$ 500,00$, sendo estes valores baseados em consulta local em uma cidade do interior. 
A carga horária de trabalho de um empreendedor, segundo os indicadores do Sebrae para o terceiro trimestre de 2018, foi de 49 horas ou mais semanais. Em relação ao rendimento mensal, a pesquisa apontou uma média mensal de 5 salários mínimos. Outro indicador da pesquisa refere-se ao número de empreendedores: no mesmo período, no Brasil foi de 27,93 milhões e no estado de Santa Catarina esse número é de 988.603 mil empreendedores. A pesquisa também aponta que $15,42 \%$ são potenciais empresários e $71,2 \%$ estão no ramo da atividade há 2 anos ou mais. E os setores de atividades dos empreendedores estão divididos em: $43,63 \%$ em serviços; $22,81 \%$ em comércio; $22,81 \%$ em construção civil; e $13,12 \%$ em indústria. Ainda como empreendedor, Eduardo precisa captar clientes, apresentar a sua empresa e a sua proposta de trabalho, negociar o contrato, diagnosticar e elaborar o plano de ação, implementar as ações, concluir o processo, gerenciar o marketing e as mídias sociais e desenvolver o material necessário de acordo com o perfil do cliente.

No decorrer do caso, Eduardo passou por alguns momentos de decisões em sua trajetória de vida e profissional que nortearam sua vida, a partir deste momento. Diante dessas considerações são propostas as seguintes questões para embasar sua decisão:

1) Quais foram as decisões tomadas por Eduardo no decorrer de sua trajetória de vida e profissional?

2) Quais os aspectos que Eduardo considerou importante nas tomadas de decisão?

3) Quais foram as atitudes empreendedoras que Eduardo vivenciou na sua trajetória?

4) Quais os fatores motivadores para empreender no caso?

5) Em que contexto estão envolvidos elementos fundamentais do empreendedorismo?

6) Quais os riscos e incertezas desta transição?

\section{NOTAS DO CASO}

\section{RESUMO DO CASO}

Este caso para ensino foi desenvolvido para auxiliar estudantes de graduação em Administração a refletir sobre a tomada de decisão para o empreendedorismo, os impactos das decisões organizacionais e a capacidade empreendedora. O caso apresenta a história do Eduardo, um jovem com emprego e garantias trabalhistas, se deparou com a oportunidade de mudar sua carreira profissional. No entanto, precisa analisar o mercado, seus conhecimentos técnicos e suas habilidades para tomar uma decisão assertiva. Neste contexto, se depara com o seguinte dilema: seguir empregado, tendo sua carreira definida pelo empregador e as garantias asseguradas em lei, tais como receitas mensais não variáveis, horários predeterminados, férias, entre outros; ou empreender no setor de prestação de serviços por meio do coaching, assumindo todos os riscos e responsabilidades do empreendimento. Este caso está relacionado aos temas de tomada de decisão e empreendedorismo.

Palavras-chave: Tomada de decisão; Empreendedorismo; Caso para ensino;

\section{PÚBLICO-ALVO}

O caso foi elaborado para utilização na graduação, em disciplinas relacionadas à área de administração, especificamente em gestão de pessoas e empreendedorismo. Poderá ser realizado em disciplinas iniciais, trazendo aspectos que podem interferir nas decisões de 
carreira, na capacidade de empreender. O caso de ensino explora questões relacionados ao empreendedorismo e tomada de decisão para empreender.

\section{OBJETIVOS DE APRENDIZAGEM}

Diante da história de vida e da trajetória profissional do protagonista Eduardo, podese abordar questões relacionadas à tomada de decisão e empreendedorismo, desta forma destaca-se alguns temas para a aprendizagem:

a) refletir sobre tomada de decisão e empreendedorismo.

b) compreender os aspectos relacionados a empreendimentos e abertura de novos negócios.

Contudo, poderão surgir novas demandas de aprendizagem, dependendo do enfoque de discussão proposto em sala de aula, como, diagnóstico organizacional, liderança, competências e valores.

DILEMA DE EDUARDO: Continuar com a carreira ou empreender no ramo de prestação de serviços com atividade de coaching?

Eduardo, um jovem de 31 anos se depara com um dilema na qual precisa tomar uma decisão em sua carreira profissional. Seguir como empregado com garantias trabalhistas ou ser um empreendedor no ramo de prestação de serviços com a atividade de coaching. Para a discussão e análise do caso deve ser considerado as seguintes possibilidades:

1- Carreira e renunciar à remuneração extra;

2- Empreender na prestação de serviços com a atividade de coaching;

3- Riscos e incertezas em ambas as decisões.

\subsection{TÓPICOS PARA DISCUSSÃO DO CASO PARA ENSINO}

1) identificar as decisões tomadas por Eduardo no decorrer de sua trajetória de vida e profissional;

2) identificar atitudes empreendedoras que Eduardo vivenciou na sua trajetória;

3) analisar os aspectos que Eduardo considerou importante nas tomadas de decisão;

4) indicar e justificar a decisão mais adequada para Eduardo;

5) identificar os riscos e incertezas de ambas as decisões.

\section{TOMADA DE DECISÃO E EMPREENDEDORISMO}

$\mathrm{Na}$ literatura, o tema empreendedorismo possui uma multiplicidade de conceitos nas diferentes áreas de conhecimento. Isto indica que há pouco consenso entre as diversas abordagens (SARASVATHY, 2001; SARASVATHY, 2008). Desta forma, opta-se pela teoria do empreendedorismo, conhecida como Effectuation (realização, em tradução livre) (SARASVATHY, 2001). A teoria do Effectuation, de acordo com Simon (1959), tem origem nos estudos acerca da Racionalidade Limitada, que associada às pesquisas da Teoria Comportamental de Cyert e March (1963), busca explicar os comportamentos humanos e a tomada de decisão do empreendedor, podendo ser adaptada a diversos contextos organizacionais.

A teoria Effectuation, é uma abordagem que estuda o empreendedor e seus comportamentos, e pode ser entendida como uma lógica de controle de um futuro imprevisível. Esta teoria se estabelece em sentido oposto a teoria Causation, que se ancora sobre bases de predição, alicerçada em planos formais para tentar prever o futuro (SARASVATHY, 2001). Entretanto, a Causation e a Effectuation não são necessariamente 
teorias opostas, mas complementares (GALKINA; LUNDGREN-HENRIKSSON, 2017). De acordo com o autor, elas podem ser aplicadas conforme a situação, podendo adotar escolhas adaptativas à realidade empreendedora que envolva risco e incerteza, ou ainda em ambientes que sejam difíceis de planejar ou prever cenários (MINTZBERG, 1994; SHANE, 2012; WELTER, 2018).

Quando se opta pela teoria Effectuation, deve-se considerar dois importantes aspectos: o primeiro deles refere-se às decisões das organizações acerca da busca pela melhoria de desempenho - com a imprevisibilidade fica mais difícil a opção de escolher um caminho de racionalidade causal; e outro, ao se levar em conta as incertezas da tomada de decisões acerca de metas a serem conhecidas apenas no futuro. Estes, assim, se constituem desafios para as teorias normativas de tomada de decisão (MINTZBERG, 1994).

Estes desafios que possibilitaram a Sarasvathy (2001, p. 245) estudar o empreendedorismo e tomada de decisão, que busca conceituar os processos Effectuation, a partir dos processos Causation e define estes como "processos que tomam um determinado efeito como dado e locus sobre a seleção entre os meios para criar esse efeito", e define os processos de Effectuation "como um conjunto de meios como dado e locus na seleção entre os possíveis efeitos que podem ser criados com esse conjunto de meios". Desta forma os processos não são estáticos e podem ocorrer de maneira simultânea, sobrepostos ou entrelaçados em diferentes contextos de decisões e ações, de certa forma, um não pode ser qualificado como melhor ou pior que outro.

Sarasvathy (2001; SARASVATHY, 2008; HENNINGER, 2020) gerou sua teoria para explicar como as novas empresas eram criadas. Para simplificar e entender, as diferenças entre as características distintivas os Processos Causation e os Processos Effectuation, apresentados na Quadro 1.

Quadro 1 - Características distintivas entre o processo do tipo Causation e do tipo Effectuation

\begin{tabular}{|c|c|c|}
\hline Diferenciação & Processos Causation & Processos Effectuation \\
\hline Dados & Efeito é dado/fornecido. & $\begin{array}{l}\text { Somente alguns meios/ferramentas são } \\
\text { dados/fornecidos. }\end{array}$ \\
\hline $\begin{array}{l}\text { Critérios de } \\
\text { seleção para } \\
\text { tomada de } \\
\text { decisão }\end{array}$ & $\begin{array}{l}\text { Ajudar a escolher entre os meios para } \\
\text { alcançar o efeito dado; Critérios de } \\
\text { seleção com base no retorno esperado; } \\
\text { Efeito dependente: A escolha dos meios } \\
\text { é impulsionada pelas características do } \\
\text { efeito que o tomador de decisão quer } \\
\text { criar e seu conhecimento dos meios } \\
\text { possíveis. }\end{array}$ & $\begin{array}{l}\text { Ajudar a escolher entre possíveis efeitos que } \\
\text { podem ser criados com determinados meios; } \\
\text { Critérios de seleção baseados em perda } \\
\text { acessível ou risco aceitável; Ator dependente: } \\
\text { dado meios específicos, a escolha do efeito é } \\
\text { conduzida pelas características do ator e sua } \\
\text { capacidade de descobrir e usar contingências. }\end{array}$ \\
\hline $\begin{array}{l}\text { Competências } \\
\text { empregadas }\end{array}$ & $\begin{array}{l}\text { Excelente na exploração do } \\
\text { conhecimento. }\end{array}$ & Excelente na exploração de contingências. \\
\hline $\begin{array}{l}\text { Contexto de } \\
\text { relevância }\end{array}$ & $\begin{array}{l}\text { Mais presente na natureza; } \\
\text { Mais útil em ambientes estáticos, } \\
\text { lineares e independentes. }\end{array}$ & $\begin{array}{l}\text { Mais onipresente na ação humana; Premissa de } \\
\text { ambientes dinâmicos, não lineares e } \\
\text { ecológicos. }\end{array}$ \\
\hline $\begin{array}{l}\text { Natureza das } \\
\text { incógnitas }\end{array}$ & $\begin{array}{l}\text { Foco nos aspectos previsíveis de um } \\
\text { futuro incerto. }\end{array}$ & $\begin{array}{l}\text { Foco nos aspectos controláveis de um futuro } \\
\text { imprevisível. }\end{array}$ \\
\hline Lógica central & $\begin{array}{l}\text { Na medida em que podemos prever o } \\
\text { futuro, podemos controlá-lo. }\end{array}$ & $\begin{array}{l}\text { Na medida em que possamos controlar o } \\
\text { futuro, não precisamos prevê-lo. }\end{array}$ \\
\hline Resultados & $\begin{array}{l}\text { Participação nos mercados existentes } \\
\text { através de estratégias competitivas. }\end{array}$ & $\begin{array}{l}\text { Novos mercados criados através de alianças e } \\
\text { outras estratégias cooperativas. }\end{array}$ \\
\hline
\end{tabular}

Fonte: Sarasvathy (2001). 


\section{PLANO DE AULA}

A aplicação do caso requer uma leitura prévia podendo ser realizado em sala com tempo médio de 30 minutos, na qual os alunos deverão responder as questões norteadoras do caso conforme seus conhecimentos prévios no tempo de aproximadamente 20 minutos.

Neste caso sugere-se que as teorias de empreendedorismo sejam passadas anteriormente, para maior aproveitamento do caso de ensino.

Após as respostas será aberta a plenária para que os alunos apresentem as suas respostas e o professor faça suas considerações identificando a teoria proposta. Para isso sugere-se que o professor conduza o debate de maneira aberta utilizando de alguns aspectos que incentivem a participação do estudante, de caráter introdutória com as perguntas:

1- Quais as percepções vocês tiveram do caso;

2- Vocês se identificam com o caso;

3- Vocês conhecem alguém ou já vivenciaram a situação de Eduardo;

A parte introdutória pode ser relacionada com o tópico de discussão; sendo eles:

I. Quais foram as decisões tomadas por Eduardo no decorrer de sua trajetória de vida e profissional?

II. Quais os aspectos que Eduardo considerou importante nas tomadas de decisão?

III. Quais foram as atitudes empreendedoras que Eduardo vivenciou na sua trajetória?

IV. Quais os fatores motivadores para empreender no caso?

V. Em que contexto estão envolvidos elementos fundamentais do empreendedorismo?

VI. Quais os riscos e incertezas de empreender?

Diante destas questões de empreendedorismo optou-se pela teoria Effectuation que considera os aspectos de imprevisibilidade e incertezas da tomada de decisão. Nesse sentido o professor pode utilizar o Quadro 1 para explanar sobre as características distintivas entre o processo do tipo Causation e do tipo Effectuation por Sarasvathy (2001).

O coaching é utilizado neste caso como aporte teórico para embasar a decisão de empreender, justamente por haver a discussão sobre as práticas do coaching e sua efetividade e embasamento teórico. A discussão com coaching não visa profundidade em conhecimento sobre a prática, mas esclarecer modismo da prática de coaching gerada no Brasil, pela disseminação somente da parte prática, excluindo o rigor científico das abordagens de coaching existentes no cenário mundial.

Para finalizar a aplicação do caso sugere-se que o professor solicite aos alunos um memorial descritivo acerca dos aspectos teóricos mais relevantes para o processo de ensino aprendizagem abordando a justificativa para cada uma das decisões, empreender, seguir na carreira atual ou buscar outra carreira.

Por fim, fazer um fechamento reflexivo sobre tomada de decisão para o empreendedorismo, explicitando, especificamente a causa e efeito das decisões e os principais fatores relacionados à decisão de iniciar um novo empreendimento.

\section{Agradecimentos}

O presente trabalho foi realizado com apoio da Coordenação de Aperfeiçoamento de Pessoal de Nível Superior - Brasil (CAPES) - Código de Financiamento 001.

\section{REFERÊNCIAS}

CYERT, Richard M.; MARCH, J. G A behavioral theory of the firm. Englewood Cliffs, NJ, v. 2, n. 4, p. 169-187, 1963. 
GALKINA, Tamara; LUNDGREN-HENRIKSSON, Eva-Lena. Coopetition as an entrepreneurial process: Interplay of causation and effectuation. Industrial Marketing Management, Amsterdam, v. 67, p. 158-173, 2017. DOI: https://doi.org/10.1016/j.indmarman.2017.09.004

HENNINGER, P.; BREM, A.; GIONES, F.; BICAN, P. M.; WIMSCHNEIDER, C. Effectuation vs. Causation: can established firms use start-up decision-making principles to stay innovative? International Journal of Innovation Management, New Jersey, v. 24, n. 01, p. 2050002, 2020._DOI: https://doi.org/10.1142/S1363919620500024

MARCH, James G.; SIMON, Hernert A. Organizations John Wiley \& Sons. New York, 1958.

MINTZBERG, Henry. The fall and rise of strategic planning. Harvard business review, Boston, v. 72, n. 1, p. 107-114, 1994.

PETERSON, David B. Executive coaching at work: The art of one-on-one change. Consulting Psychology Journal: Practice and Research, Stanford, v. 48, n. 2, p. 78, 1996.

SARASVATHY, Saras D. Causation and effectuation: Toward a theoretical shift from economic inevitability to entrepreneurial contingency. Academy of Management Review, New York, v. 26, n. 2, p. 243-263, 2001. DOI: https://doi.org/10.5465/amr.2001.4378020

SARASVATHY, Saras D.; DEW, Nicholas; READ, Stuart; WILTBANK, Robert. Designing organizations that design environments: Lessons from entrepreneurial expertise.

Organization Studies, California, v. 29, n. 3, p. 331-350, 2008. DOI:

https://doi.org/10.1177/0170840607088017

SBC - Sociedade Brasileira de Coaching. Sobre o IBC. 2019. Disponível em:

http://www.ibccoaching.com.br/sobre-o-ibc/diferenciais/

SEBRAE. Dados empresas: Empreendedores. 2019. Disponível em:

http://sistema.datasebrae.com.br/sites/novo_datasebrae/\#Empreendedores

SHANE, Scott. Reflections on the 2010 AMR decade award: Delivering on the promise of entrepreneurship as a field of research. Academy of Management Review, New York, v. 37, n. 1, p. 10-20, 2012. DOI: https://doi.org/10.5465/amr.2000.2791611

SIMON, Herbert A. Theories of decision-making in economics and behavioral science. The American Economic Review, New York, v. 49, n. 3, p. 253-283, 1959. DOI:

https://www.jstor.org/stable/1809901

WELTER, Christopher; KIM, Sungho. Effectuation under risk and uncertainty: A simulation model. Journal of Business Venturing, Amsterdam, v. 33, n. 1, p. 100-116, 2018. DOI: https://doi.org/10.1016/j.jbusvent.2017.11.005 